\title{
Downregulation of both EGFR and ErbB3 improves the cellular response to pemetrexed in an established pemetrexed-resistant lung adenocarcinoma A549 cell line
}

\author{
ZHUANG YU ${ }^{1}$, XIU-MEI LI ${ }^{1}$, SHI-HAI LIU ${ }^{2}$, BING LIU ${ }^{3}$, CAI-HONG GAO ${ }^{1}$ and XIN HOU ${ }^{1}$ \\ ${ }^{1}$ Department of Oncology and ${ }^{2}$ Central Laboratory, The Affiliated Hospital of Qingdao University, Qingdao 266003; \\ ${ }^{3}$ Department of Medicine, The Commercial Workers' Hospital of Qingdao, Qingdao 266011, P.R. China
}

Received December 15, 2013; Accepted February 6, 2014

DOI: $10.3892 /$ or.2014.3027

\begin{abstract}
Epidermal growth factor receptor(EGFR) and ErbB3 (HER3) play important roles in the regulation of cell proliferation, differentiation, anti-apoptosis and chemoresistance; however, their dysregulation in pemetrexed (PEM) resistance remains unclear. The aim of the present study was to clarify the relationship between PEM resistance and gene expression of EGFR and ErbB3, by establishing the PEM-resistant lung adenocarcinoma A549 cell line, A549/PEM. Compared with A549 cells, the A549/PEM cells were significantly more resistant to PEM $(\mathrm{P}=0.0024)$. The downregulation of $\mathrm{S}$ phase and arrest at G1 stage were detected in the A549/PEM cell line when compared to the A549 cells $(\mathrm{P}<0.05)$. The apoptosis rate of A549/PEM cells was much lower than that of the A549 cells after a $24 \mathrm{~h}$ continuous exposure to PEM $(\mathrm{P}<0.001)$. Real-time PCR and western blotting demonstrated the overexpression of EGFR and ErbB3 in A549/PEM cells. However, downregulation of EGFR or ErbB3 by lentiviral delivered shRNAs in A549/PEM cells showed no significant correlation with PEM sensitivity while silencing both EGFR and ErbB3 increased the cellular response to PEM in the A549/PEM cells and significantly decreased phosphorylation of STAT3, AKT and ERK. Together, these data suggest that either high expression of EGFR or ErbB3 plays a critical role in the cellular response to PEM in human lung adenocarcinoma cells though EGFR/ErbB3-dependent pathways.
\end{abstract}

\section{Introduction}

Lung cancer is the most common cause of cancer-related mortality in the world (1). Non-small cell lung cancer (NSCLC)

Correspondence to: Dr Zhuang Yu, Department of Oncology, The Affiliated Hospital of Qingdao University, 16 Jiangsu Road, Qingdao 266003, P.R. China

E-mail: zhyumed@126.com

Key words: epidermal growth factor receptor, ErbB3, pemetrexed, resistance, lung adenocarcinoma, A549 cells accounts for $\sim 80-85 \%$ of lung cancer cases, and small cell lung cancer (SCLC) accounts for the remaining 15-20\%. More than half of patients with NSCLC are diagnosed at an advanced stage (stage III or IV), and chemotherapy is often the first choice of treatment for these patients $(2,3)$. However, the response to chemotherapy as well as the associated prognosis remains unfavorable.

Pemetrexed (PEM) is a multi-targeted antifolate drug that disrupts multiple enzymes involved in pyrimidine and purine synthesis (4). It has been approved for the treatment of NSCLC (5). Combination chemotherapy with PEM and cisplatin has better tolerability compared to cisplatin, and have been used as first-line treatment or as single drugs for maintenance therapy in advanced NSCLC patients (6-8). A phase III trial outlined that patients with adenocarcinoma treated with a PEM-based regime had prolonged overall survival than those with squamous cell carcinoma (7). However, the majority of lung adenocarcinoma patients treated with PEM exhibit either intrinsic or acquired resistance. Previous research of PEM resistance has primarily focused on enzymes in the folate metabolic pathway, and some researchers have found that overexpression of thymidylate synthase (TS) and dihydrofolate reductase (DHFR) is associated with insusceptibility to PEM $(9,10)$. Yet, one recent study found that PEM-treated lung adenocarcinoma patients with EGFR mutations had a better response rate and longer progression-free survival (11). However, whether EGFR expression is associated with PEM-resistance in NSCLC has not yet been reported.

The epidermal growth factor receptor (EGFR) and ErbB3 (HER3) are members of the ErbB family of receptor tyrosine kinases. They play a critical role in processes such as neoplastic cell proliferation, anti-apoptosis, angiogenesis and metastasis. Generally speaking, ErbB gene expression has a negative correlation with clinical outcome (12). EGFR overexpression and mutations are found in lung adenocarcinoma, and its overexpression is recognized in many types of human cancers, including breast, colorectal and gastric cancer (13-15). High expression of EGFR is often associated with aggressive phenotypes and resistance to chemotherapy, and it is used as a multi-drug resistant marker in certain types of cancer $(16,17)$. ErbB3 is considered to stimulate intracellular signaling coupled with other ErbB family members. 
Novel therapies or combinations blocking ErbB3 may provide strategies to overcome acquired resistance and to increase the effectiveness of therapy (18). EGFR and ErbB3 inhibited the cellular response to sorafenib in hepotocellular cell lines (19). In addition, our preliminary experiments revealed that PEM may be used beneficially in combination with EGFR. This suggests that PEM has an antitumor effect by acting on the EGFR and its family members.

To the best of our knowledge, this is the first study to investigate the association of expression of the ErbB genes and PEM resistance. In the present study, we established a PEM-resistant lung adenocarcinoma cell line and provided a model with which to explore relevant factors of acquired resistance to PEM. By comparison with to the parental cell line, we aimed to elucidate the correlation between EGFR and ErbB3 expression and PEM resistance. This may provide novel predictive markers for the clinical application of PEM.

\section{Materials and methods}

Preliminary experiments. The docking analysis was performed with the Surflex-Dock model. The crystal structure of the EGFR-erlotinib complex was collected from a protein data bank (PDB code: 1M17). All of the hydrogen atoms were added to define the correct configuration and tautomeric states. Then the model structure was energy-minimized, and the Powell energy minimization algorithm was used for energy minimization. After extracting the binding ligand erlotinib, PEM was then docked into the binding pocket for dockingscoring analysis (20).

Cell culture. The human lung adenocarcinoma cell line A549 was obtained from the Cell Resource Center of the Shanghai Institutes for Biological Sciences. A549 cells were cultured in RPMI-1640 medium supplemented with $10 \%$ fetal bovine serum (FBS) (both from Gibco, Carlsbad, CA, USA), $100 \mathrm{U} / \mathrm{ml}$ of penicillin $\mathrm{G}$, and $100 \mu \mathrm{g} / \mathrm{ml}$ of streptomycin, and cells were cultivated in a incubator with $5 \% \mathrm{CO}_{2}$ at $37^{\circ} \mathrm{C}$ under humidified conditions.

Establishment of the PEM-resistant cell line. The A549 cell line was exposed to a single high concentration of PEM (the $50 \%$ inhibitory concentration of PEM for A549 cells) over a period of $48 \mathrm{~h}$ repeatedly $(10,12)$. PEM was obtained from Eli Lilly and Company (Indianapolis, IN, USA; A762406C). The treated cells were then washed with diluted phosphatebuffered saline (PBS) and cultured in fresh growth medium without PEM every day until all the dead cells were washed out. After that, the surviving cells were cultivated as normal cells. The treated A549 cells recovered and exhibited logarithmic growth after 2 weeks. When cells were growing exponentially and subcultured with trypsin, these cells were again exposed to PEM for $48 \mathrm{~h}$. The degree of resistance of the treated cells was detected discontinuously until it was in accordance with the requirement of the experiment. The PEM-resistant cell line was established after 5 months, and it was named A549/PEM. Then the resistant cells were cultured in an incubator with $5 \%$ $\mathrm{CO}_{2}$ at $37^{\circ} \mathrm{C}$ for 1 month and passed several generations. The resistance was detected again, and the A549/PEM cell line was proven to acquire stable resistance. The resistant cells were used for subsequent experiments after another month of culture in PEM-free medium.

Growth inhibition assay. Growth inhibition of the cells was detected by the CCK-8 assay (Dojindo Molecular Technologies, Kumamoto, Japan). Cells $(2,000)$ were added into every well of a 96-well flat bottomed microplate and cultured in $100 \mu \mathrm{l}$ RPMI-1640 medium supplemented with 10\% FBS. The cells were divided into 7 group with different concentrations of PEM. The cells were incubated at $37^{\circ} \mathrm{C}$ for $24 \mathrm{~h}$ in a humidified incubator with $5 \% \mathrm{CO}_{2}$. Subsequently, the PEM concentrations were $0.001,0.01,0.1,1.0,10,100$ and $1,000 \mu \mathrm{g} / \mathrm{ml}$, respectively. The well without PEM was set as the control group. Those wells with $100 \mu \mathrm{l}$ nutrient solution only were considered as the blank control. After incubating for $48 \mathrm{~h}$, the drug-containing growth medium was replaced with $110 \mu \mathrm{l}$ medium containing CCK-8 reagent (10 $\mu \mathrm{l} \mathrm{CCK-8}$ and $100 \mu \mathrm{l}$ RPMI). Following lucifuge culturing for $2 \mathrm{~h}$, the optical density (OD value) was measured for each well $(450 \mathrm{~nm})$ by an automated spectrophotometer. The resistance of the A549/PEM cell lines was calculated according to the OD values. Each assay was performed in quintuplicate at least 3 times.

The absorbance values at $450 \mathrm{~nm}$ in the experimental wells relative to the initial value indicated cell growth or death, respectively. The following formula was used to calculate the surviving cell fraction: 1 - [(mean absorbance of experimental cells - mean absorbance of blank control cells)/(mean absorbance of control cells - mean absorbance of blank control cells)] x $100 \%$ (10). The mean and standard deviation (SD) were calculated, respectively. The lower the $\mathrm{IC}_{50}$ value, the higher was the ability for inhibition of cell proliferation (21).

Flow cytometric analysis. A cell cycle analysis kit was obtained from Beyotime Biotechnology Co. Ltd. (Shanghai, China). A single-cell suspension of A549 and A549/PEM cells was collected respectively, and washed with ice-cold PBS 3 times, and then the cells were fixed with ice-cold $70 \%$ ethanol for $30 \mathrm{~min}$. The supernatant was discarded after centrifugation, and the cells were again washed with cold PBS twice. These cells were then treated with RNase for $30 \mathrm{~min}$ at $37^{\circ} \mathrm{C}$. Subsequently, the cells were dyed with propidium iodide (PI), for analysis of the cell cycle by flow cytometry (FCM).

A549 and A549/PEM cells were cultured for $24 \mathrm{~h}$ with media containing PEM at a final concentration of $0.5 \mu \mathrm{g} / \mathrm{ml}$. A single-cell suspension $\left(1-5 \times 10^{6}\right)$ was washed twice with cold PBS, and the supernatant fluid was discarded by centrifugation. Then cells were fixed with $70 \%$ ethanol at $4^{\circ} \mathrm{C}$ overnight. Cells were resuspended with $100 \mu \mathrm{l} 1 \mathrm{X}$ Annexin-binding buffer, and then $5 \mu \mathrm{l}$ Annexin $\mathrm{V}$ and $5 \mu \mathrm{l}$ PI (Invitrogen Life Technologies Corporation, Carlsbad, CA, USA) was added to each column. Subsequently, cells were incubated for $15 \mathrm{~min}$ at $37^{\circ} \mathrm{C}$ without light. After adding $400 \mu 11 \mathrm{X}$ Annexin-binding buffer, cells in the ice were detected by FCM within 30 min. The early apoptotic cells (Annexin V-positive, PI-negative), late apoptotic cells (double-positive) and living cells (doublenegative) (12) were detected by FCM and subsequently analyzed by CellQuest software (Becton-Dickinson, USA).

Construction and infection of short hairpin RNAs. Silencing of gene expression was achieved using short hairpin RNA 
(shRNA) technology. shRNAs targeting EGFR (sense, 5'-CAC CGA AGA CGA CAC CGC CTC ACC TCC ACC GTG CAA CTC ATC ACG CTT CAA GAG AGC G-3' and antisense, 5'-TGA GGG ATC CAA AAA ACT CAC CTC CAC CGT GCA ACT CAT CAC GCT CTC TTG AAG CGG G-3'); and/or ErbB3 (sense, 5'-CCG GAA TAT TCG CCC AAC CTT TAA ACT CGA GTT TAA AGG TTG GGC GAA TAT TTT TTT G-3' and antisense, 5'-AAT TCA AAA AAA TAT TCG CCC AAC CTT TAA ACT CGA GTT TAA AGG TTG GGC GAA TAT T-3') were cloned into PLKO.1-Puro plasmid (Addgene, Cambridge, MA, USA). Lentiviral particles containing PLKO.1 (empty vector control, sh-control), PLKO.1-anti-EGFR shRNA (shEGFR) and PLKO.1-antiErbB3 shRNA (shErbB3) were produced. For infection, A549/ PEM cells were grown in $75 \mathrm{~mm}^{2}$ flasks and transduced at $60 \%$ confluency with $10 \mathrm{ml}$ HEK-293T medium containing virions, in the presence of polybrene $(10 \mu \mathrm{g} / \mathrm{ml})$. After $48 \mathrm{~h}$, the expression of mRNA and protein was determined by real-time PCR and western blotting, respectively.

Relative quantitative real-time PCR. Total RNA was extracted from A549 and A549/PEM cells using TRIzol reagent (Gibco). The concentration and purity of RNA were determined by measuring the absorbance at $260 \mathrm{~nm}$ using a NanoDrop ${ }^{\circledR}$ ND-1000 spectrophotometer (Thermo Scientific, Wilmington, DE, USA). Reverse transcription was proceeded with PrimeScript ${ }^{\circledR}$ reverse transcriptase (Takara Bio, Tokyo, Japan) at $37^{\circ} \mathrm{C}$ for $15 \mathrm{~min}$, and at $85^{\circ} \mathrm{C}$ for $5 \mathrm{sec}$, and then chilled at $4^{\circ} \mathrm{C}$ immediately. The generated cDNA samples were stored at $-20^{\circ} \mathrm{C}$.

Real-time PCR was performed using PCR amplification equipment (Roche Diagnostics, Basel, Switzerland). The reaction mix of $20 \mu \mathrm{l}$ contained PCR forward primer $1.6 \mu \mathrm{l}(5 \mu \mathrm{M})$, PCR reverse primer $1.6 \mu \mathrm{l}(5 \mu \mathrm{M})$, cDNA $2.0 \mu \mathrm{l}$, SYBR Premix Ex Taq II (Takara Bio) $10.0 \mu 1$ and ultrapure water 4.8 $\mu 1$. PCR reactions were performed under the following conditions: $95^{\circ} \mathrm{C}$ for $10 \mathrm{sec}$ followed by $1 \mathrm{cycle}$ at $95^{\circ} \mathrm{C}$ for $5 \mathrm{sec}, 60^{\circ} \mathrm{C}$ for $20 \mathrm{sec}$, and $72^{\circ} \mathrm{C}$ for $20 \mathrm{sec}$ followed by 40 cycles. Glyceraldehyde-3phosphate dehydrogenase (GAPDH) was used as the internal control, since its expression has been demonstrated to remain stable during the protocol (10). The standard curves and the threshold cycle $(\mathrm{Ct})$ of target genes were obtained from the instrument's software. The relative expression of mRNA was

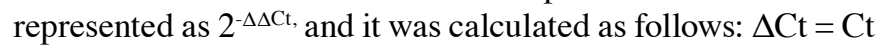
(target gene) - $\mathrm{Ct}(\mathrm{GAPDH}), \Delta \Delta \mathrm{Ct}=\Delta \mathrm{Ct}$ (treatment) $-\Delta \mathrm{Ct}$ (control), and $\mathrm{R}=2-[\Delta \mathrm{Ct}$ (treatment) $-\Delta \mathrm{Ct}$ (control)] (22).

All primers used in the present study were designed by Sangon Biotech Co. Ltd. (Shanghai, China). The primer sequences were as follows: EGFR forward primer, 5'-AGG CAC GAG GAA CAA GCT CAC-3' and reverse primer, 5'-ATG AGG ACA TAA CCA GCC ACC-3'; ErbB3 forward primer, 5'-TGC TGA GAA CCA ATA CCA GACA-3' and reverse primer, 5'-CTG TCA CTT CAC GAA TCC ACTG-3'; GAPDH forward primer, 5'-CTG CAC CAC CAA CTG CTT AG-3' and reverse primer, 5'-TGA AGT CAG AGG AGA CCA CC-3'.

Western blotting. Whole-cell proteins in the A549 and A549/ PEM cell lines were isolated. The lysates were centrifuged, and the supernatant was collected and stored at $-80^{\circ} \mathrm{C}$ according to the manufacturer's instructions. Total protein $(10 \mu \mathrm{g})$ was loaded per well, separated by $10-15 \%$ SDS-PAGE, and transferred to polyvinylidene difluoride membranes at $60 \mathrm{~V}$ for $1 \mathrm{~h}$ at $4^{\circ} \mathrm{C}$. The membranes were blocked and incubated with primary antibodies (Bioworld Co., USA; diluted 1:1,000 in TBS-A). The membranes were rinsed thrice with $1 \%$ Tween-20-PBS for $30 \mathrm{~min}$. The secondary antibodies (Abcam Co., Cambridge, UK; diluted 1:1,200 in TBS-A) were used with peroxidase-conjugated AffiniPure goat anti-mouse $\operatorname{IgG}(1: 8,000)$ and peroxidase-conjugated AffiniPur goat antirabbit $\operatorname{IgG}(1: 8,000)$ for $1 \mathrm{~h}$ at room temperature. The blotted membranes were washed 3 times with $0.1 \%$ Tween-20-PBS for 15 min and 3 times with PBS for 15 min. The immunoblots were detected using an electrochemiluminescence kit and exposed to the Vilber Fusion FX5 automatic gel imaging analysis system (Vilber, Marne La Vallée, France).

Statistical analysis. Differences between resistant cells and parental cells were analyzed using Student's t-test. All statistical analysis was performed with SPSS 13.0 software. $\mathrm{P}<0.05$ was considered to indicate a statistically significant result.

\section{Results}

Molecular docking. The docking studies indicated that PEM may bind to the pocket of the EGFR (Fig. 1). In the model, PEM was nicely bound to $1 \mathrm{M} 17$ and had hydrogen bonds, and the score was 6.22 by the SYBYL 7.3 software. The length of the hydrogen bonds formed between PEM and GLU738, GLY772, ALA719, CYS773 and MET769 were 2.093, 2.424, $2.228,2.035$ and $2.048 \AA$, respectively.

EstablishmentofthePEM-resistantcell line. The PEM-resistant cell line A549/PEM was successfully induced after 5 months. In the CCK-8 assay, the $\mathrm{IC}_{50}$ values of PEM for A549 and A549/PEM cells were $0.22 \pm 0.04$ and $4.37 \pm 0.26 \mu \mathrm{g} / \mathrm{ml}$, respectively. The A549/PEM cell line was significantly more resistant than the A549 cell line to PEM ( $\mathrm{P}=0.0024)$ (Fig. 3), and the resistant index (RI) was 19.86. The morphologic observation showed that most of the cells died after being treated with PEM. The volume of the surviving cells was altered. Cells had an irregular shape, and the cell membrane was vague (Fig. 2). A549/PEM cells showed a longer doubling time than the parental cell line ( $33.5 \pm 1.71$ vs. $27.1 \pm 1.15 \mathrm{~h}, \mathrm{P}=0.02)$.

Flow cytometric analysis revealed significant apoptosis after A549 cells were exposed to a high concentration $\left(5 \times 10^{-5} \mathrm{~mol} / \mathrm{l}\right)$ of PEM for $24 \mathrm{~h}$, whereas A549/PEM cells showed a much lower apoptosis rate $(\mathrm{P}<0.001)$ (Fig. 4). The percentage of apoptotic A549 cells increased from 2.6 $\pm 0.1 \%$ (without exposure to PEM) to $23.52 \pm 3.2 \%$ (with exposure to PEM) $(\mathrm{P}<0.001)$. The percentage of apoptotic A549/PEM cells increased from $1.7 \pm 0.1 \%$ (without exposure to PEM) to $4.16 \pm 2.1 \%$ (with exposure to $\mathrm{PEM})(\mathrm{P}=0.072)$. In addition, the percentages of cells in the G1/G0, S and G2/M phases were analyzed. The number of cells in the G1/G0 phase increased, and that in the $S$ phase decreased in the A549/PEM cells $(\mathrm{P}<0.05)$ (Table I).

Expression of EGFR and ErbB3 in the A549 and A549/PEM cells. The mRNA expression of EGFR in the A549 and 


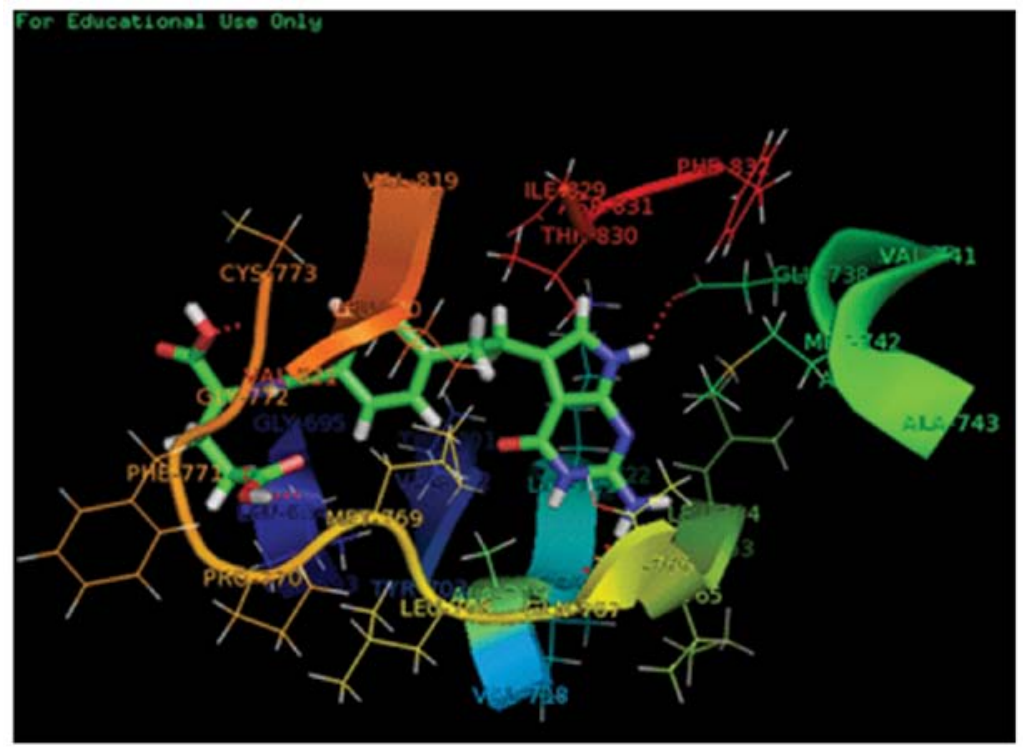

Figure 1. 3D model of the interaction between PEM and the 1M17 binding site.
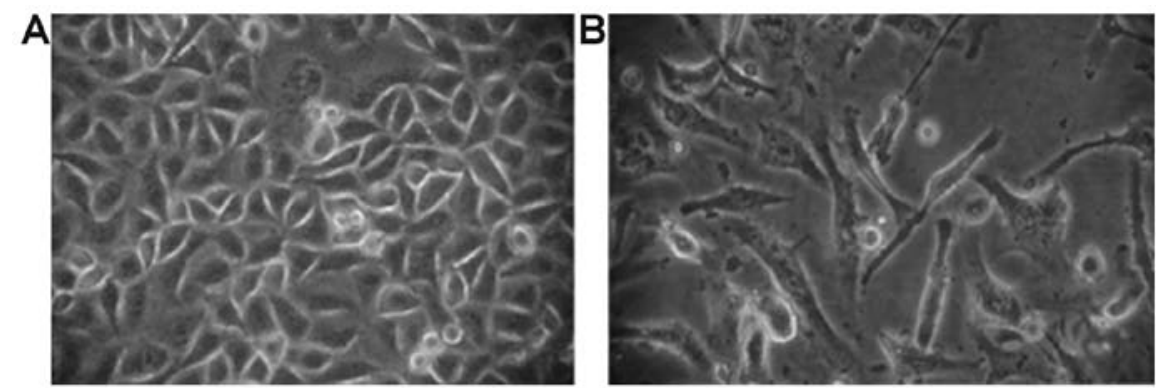

Figure 2. Cell morphology of (A) A549 cells and (B) A549 cells with pemetrexed (x100). Most of the A549 cells died after being treated with PEM. The volume, shape and membrane were altered in the surviving cells. PEM, pemetrexed.

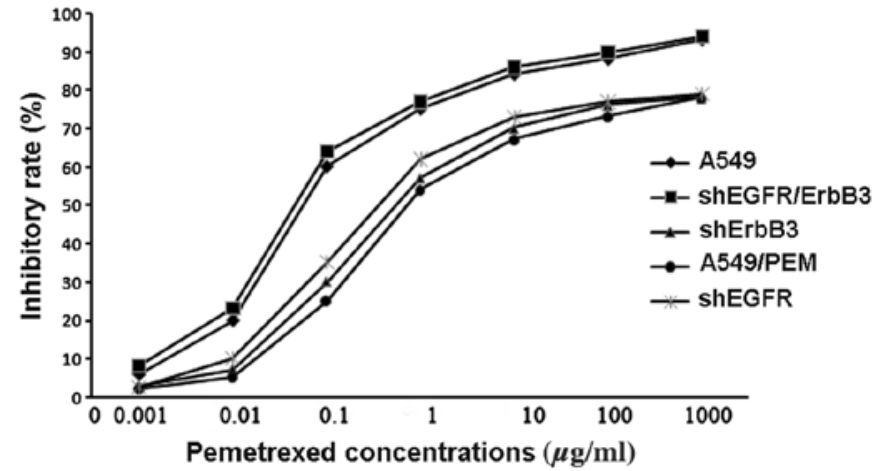

Figure 3. A549 and A549/PEM cells were treated with various concentrations of pemetrexed $(0.001,0.01,0.1,1,10,100$ and $1000 \mu \mathrm{g} / \mathrm{ml})$ for $48 \mathrm{~h}$ for the CCK-8 assay. The inhibitory growth rate of infected A549/PEM cells, uninfected A549/PEM cells and A549 cells are shown. The sensitivity to chemotherapeutic drugs (pemetrexed) of A549/PEM cells increased after interference of both EGFR and ErbB3, and the difference was statistically significant $(\mathrm{P}<0.05)$. $\mathrm{PEM}$, pemetrexed.

A549/PEM cells was $0.87 \pm 0.08$ and $2.01 \pm 0.12$, respectively $(\mathrm{P}=0.0089)$ (Fig. 5A). ErbB3 mRNA expression in the two cell lines was $0.96 \pm 0.04$ and $2.31 \pm 0.22$, respectively $(\mathrm{P}=0.034)$. Compared with the parental cell line, the EGFR and ErbB3
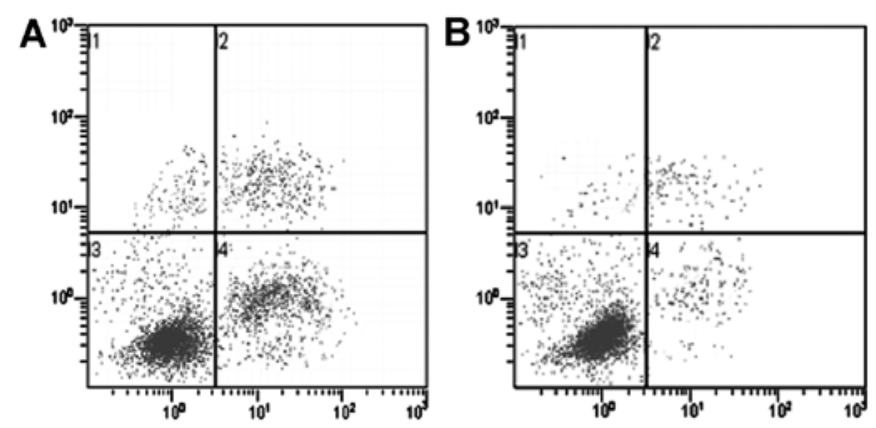

Figure 4. Apoptosis of (A) A549 and (B) A549/PEM cells following treatment with PEM. Cells were treated with $0.5 \mu \mathrm{g} / \mathrm{ml}$ of PEM for $24 \mathrm{~h}$, and then apoptosis was detected by flow cytometric DNA analysis after nuclear staining with Annexin V and PI. PEM, pemetrexed.

expression levels were significantly higher. Western blotting was used to analyze their expression at the protein level. The gray scale of the stained area was measured under identical conditions. Higher average optical densities for EGFR and ErbB3 were observed in the A549/PEM cells when compared with that in the parental cell line (Fig. 5B). The difference was statistically significant $(\mathrm{P}<0.05)$. 
Table I. Quantitative assessment of the cell cycle distribution of A549 and A549/PEM cells.

\begin{tabular}{lccc}
\hline & \multicolumn{3}{c}{ Cell cycle phases } \\
\cline { 2 - 4 } Cell lines & G1/G0 (\%) & $\mathrm{S}(\%)$ & $\mathrm{G} 2 / \mathrm{M}(\%)$ \\
\hline A549 & $58.05 \pm 1.37$ & $37.63 \pm 1.25$ & $4.32 \pm 1.15$ \\
A549/PEM & $66.09 \pm 1.63^{\mathrm{a}}$ & $30.03 \pm 0.91^{\mathrm{a}}$ & $3.88 \pm 1.01$ \\
\hline
\end{tabular}

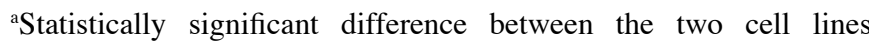
$(\mathrm{P}<0.05)$. PEM, pemetrexed.
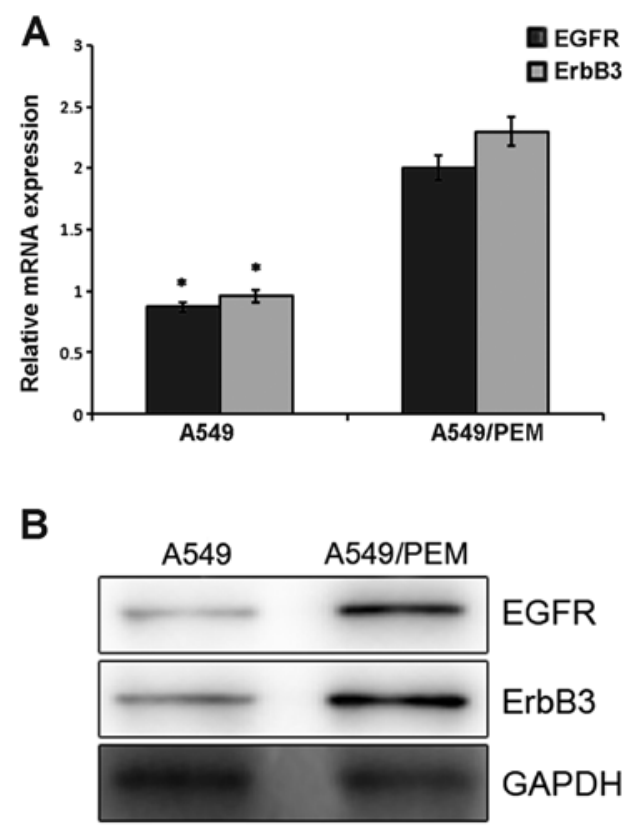

Figure 5. (A) mRNA expression of EGFR and ErbB3 in the A549 and A549/PEM cells was detected by real-time PCR. "Statistically significant difference $(\mathrm{P}<0.05)$. (B) Protein levels of EGFR and ErbB3 in the A549 and A549/PEM cells. EGFR, epidermal growth factor receptor; PEM, pemetrexed.

Expression levels of EGFR and ErbB3 in the A549/PEM cells following EGFR, ErbB3 or EGFR/ErbB3 downregulation. Following lentiviral infection of the A549/PEM cell line, the mRNA expression of EGFR and ErbB3 was examined by realtime PCR. As shown in Fig. 6A, a significant difference was noted between the silenced and control cells $(\mathrm{P}<0.05)$. The relative level of EGFR mRNA in the A549/PEM-shEGFR cells was significantly downregulated by 2.4 -fold when compared with that in the A549/PEM-sh-control cells. In the A549/PEM cells infected with ErbB3 shRNA, we observed that the level of ErbB3 mRNA was successfully downregulated by 2.5 -fold compared with that in the A549/PEM-sh-control cells.

The protein expression of EGFR and ErbB3 was evaluated by western blotting. The average optical density for EGFR protein expression in the shEGFR-infected cells was lower when compared with the value in the A549/PEM-shcontrol cells. The observed differences were significant $(\mathrm{P}<0.05)$ (Fig. 6B). Consistent with the above mRNA results,
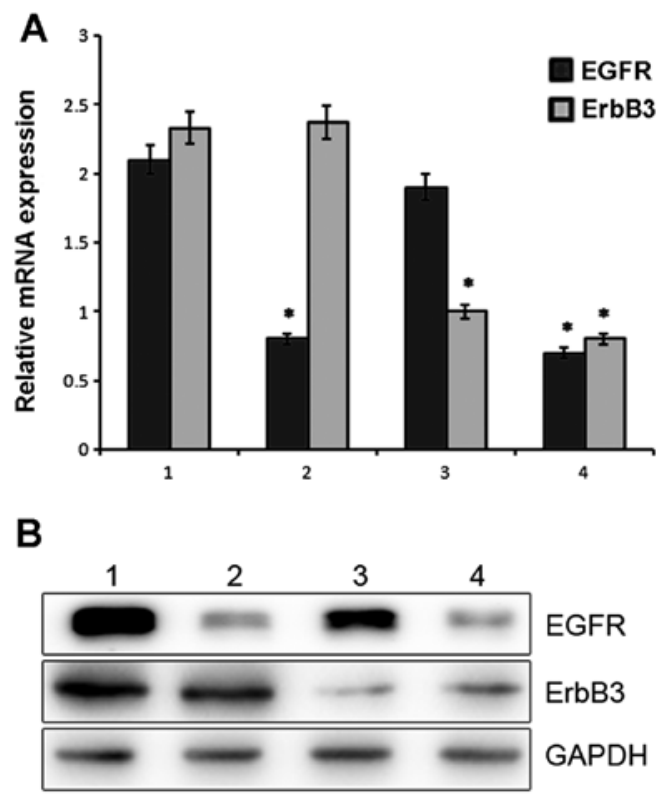

Figure 6. (A) mRNA levels of EGFR and ErbB3 as detected by real-time PCR after A549/PEM cells were infected with lenti-shEGFR or lenti-shErbB3. EGFR-shRNA-infected cells exhibited significantly lower EGFR mRNA expression $(0.84 \pm 0.07)$ when compared with that of the control group (2.05 \pm 0.06$)$. The relative expression of ErbB3 in the A549/PEM-shErbB3 and A549/PEM-shEGFR/ErbB3 cells was $1.02 \pm 0.03$ and $0.91 \pm 0.021$, respectively. *Statistically significant difference $(\mathrm{P}<0.05)$. (B) Protein levels of EGFR and ErbB3 after A549/PEM cells were infected with lenti-shEGFR or lenti-shErbB3 as detected by western blotting $(\mathrm{P}<0.05)$. lenti-shEGFR or lenti-shErbB3 significantly knocked down expression of EGFR and ErbB3 at the protein level $(\mathrm{P}<0.05)$, compared with the lenti-sh-control. Lane 1, A549/PEM cells infected with lenti-sh-control; lane 2, A549/PEM cells infected with lenti-shEGFR; lane 3, A549/PEM cells infected with lenti-shErbB3; lane 4, A549/PEM cells infected with lenti-shEGFR/ErbB3. EGFR, epidermal growth factor receptor; PEM, pemetrexed.

the average optical density for ErbB3 protein expression in the A549/PEM-shErbB3, A549/PEM-shEGFR/ErbB3 and A549/PEM-sh-control cells showed significant differences between the cell groups $(\mathrm{P}<0.05)$. The results were in accordance with the mRNA levels.

Cellular response to PEM following downregulation of EGFR or ErbB3. A549/PEM cells that overexpress EGFR and ErbB3 are more resistance to PEM than A549 cells that do not overexpress EGFR and ErbB3. After inhibiting EGFR expression, the $\mathrm{IC}_{50}$ value (index of chemotherapy sensitivity to PEM) of the EGFR-shRNA-infected cells was $4.52 \pm 0.47 \mu \mathrm{g} / \mathrm{ml}$, and this value for A549/PEM was $4.37 \pm 0.26 \mu \mathrm{g} / \mathrm{ml}(\mathrm{P}=0.33)$. The $\mathrm{IC}_{50}$ value of the ErbB3-shRNA infected cells that reduced the expression of ErbB3 was $4.46 \pm 0.31 \mu \mathrm{g} / \mathrm{ml}(\mathrm{P}=0.42)$. This difference was not statistically significant (Fig. 3). Following the silencing of both EGFR and ErbB3, the $\mathrm{IC}_{50}$ value detected by CCK- 8 assay was $0.19 \pm 0.17 \mu \mathrm{g} / \mathrm{ml}(\mathrm{P}=0.0015)$. These results indicate that overexpression of EGFR or ErbB3 may increase the cell resistance to PEM treatment.

Effects of the downregulation of EGFR, ErbB3 or EGFR/ErbB3 on EGFR/ErbB3-dependent pathways in the A549/PEM cell lines. We next investigated the mechanistic basis for the resistance to PEM of the A549/PEM cells (A549/ PEM-sh-control, A549/PEM-shEGFR, A5490PEM-shErbB3 


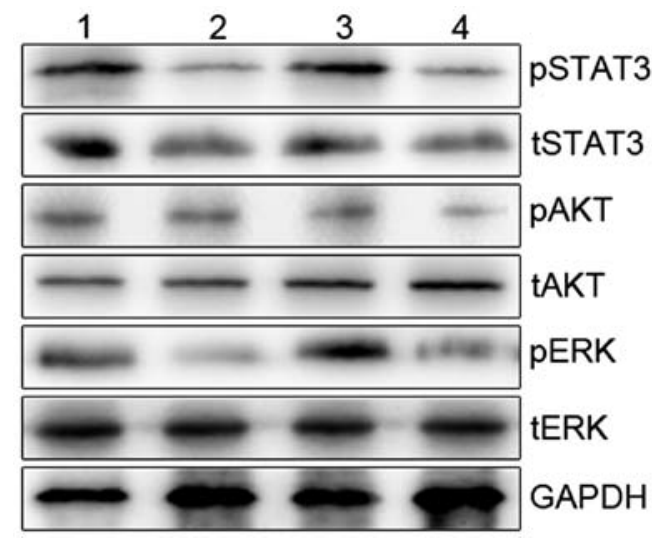

Figure 7. Phosphorylated and total protein levels of STAT3, AKT and ERK were evaluated by western blotting. Blots were quantified by scanning densitometry. Phosphorylation of STAT3, AKT and ERK in the A549/PEM cells infected with lenti-shEGFR/ErbB3 was significantly lower than control cells $(\mathrm{P}<0.05)$. Lane 1, A549/PEM cells infected with lenti-sh-control; lane 2, A549/PEM cells infected with lenti-shEGFR; lane 3, A549/PEM cells infected with lenti-shErbB3; lane 4, A549/PEM cells infected with lenti-shEGFR/ErbB3. PEM, pemetrexed; EGFR, epidermal growth factor receptor.

and A549/PEM-shEGFR/ErbB3). Phosphorylation of STAT3, AKT and ERK was inhibited by knockdown of both EGFR and ErbB3 $(\mathrm{P}<0.05)$, whereas these levels were mildly suppressed by silencing of ErbB3 alone ( $>>0.05)$ (Fig. 7). Downregulation of EGFR resulted in marked inhibition of the phosphorylation of STAT3 and ERK. We provide proof that dual silencing of EGFR and ErbB3 in A549/PEM cells improved the sensitivity to PEM. We observed that the phosphorylation of STAT3, AKT and ERK in the A549/PEM-shEGFR/ErbB3 cells was markedly abrogated.

\section{Discussion}

Drug resistance is a great obstacle to the successful treatment of NSCLC. To data, it has been shown that lung cancer multidrug resistance involves a variety of mechanisms, including expression of drug transporters, activation of detoxification system, structural change in targets or inactivation of tumorsuppressor genes and activation of oncogenes (23). However, no single mechanism can reasonably explain the primary or secondary chemotherapy resistance phenomenon. For this reason, inducing drug-resistance in cell lines in vitro is an important method with which to study the mechanisms of chemotherapy resistance and investigate the functions of potential resistance-induced genes or proteins (24). PEM-resistant A549 cell lines have been reported in a previous study. The cell lines were exposed to step-wise increasing concentrations of PEM (10). Cells show low resistance when the resistance index (RI) is $<5$-fold, moderate resistance when RI is 5-15, and high resistance when RI is $>15$-fold (25). Here, we established a PEM-resistant lung adenocarcinoma cell line successfully through high concentration intermittence, named A549/PEM, with RI of 19.86. The A549/PEM cell line showed a lower apoptosis rate than the A549 cells following treatment with PEM. Previous in vitro experiments suggest that antifolate drugs can affect the cell cycle, and cells are arrested in the
G1 phase $(26,27)$. It is generally acknowledged that when the cycle of tumor cell proliferation is short, the drugs targeting the DNA synthesis process are more sensitive. Under contrary, conditions, the sensitivity is reduced (28). The percentage of A549/PEM cells in the S phase was decreased while the percentage in the G1/G0 phase was increased. Thus, cells in the DNA synthesis phase were decreased and cell proliferation was slowed down. This is agreement with other research results, and it may be one of the reasons for the resistance to PEM.

Although the relationship between expression of TS, DHFR, GARFT genes and PEM resistance has been demonstrated $(29,30)$, we focused on ErbB genes since high expression of EGFR and ErbB3 was observed in our established PEM-resistant cell line. Further investigation confirmed that downregulation of both EGFR and ErbB3 in A549/PEM cells by lentiviral infection reversed the cell resistance to PEM. These findings suggest that a high expression level of EGFR or ErbB3 is one of the resistance factors for PEM. The chromosomes of lung adenocarcinoma cells are damaged by PEM (31), and the function of damaged chromosomes may be recovered by upregulation of EGFR or ErbB3, thus reducing the effect of PEM. In addition, cell signal transduction and regulation mechanisms are attributed to tumor resistance. The major signal transduction pathways that ultimately result in proliferative signals to the cell nucleus include Ras/Raf/MEK/ERK/ MAPK, PI3K/AKT and JAK/STAT pathways $(32,33)$. The altered expression of EGFR and ErbB3 and activity of these signaling pathways may influence the resistance of lung adenocarcinoma cells to PEM. Thus, further study was performed to explore those pathways. Downregulation of EGFR and/or ErbB3 was found to result in a decrease in the phosphorylation of STAT3, AKT and ERK in the A549/PEM cell line. However, A549/PEM-shEGFR and A549/PEM-shErbB3 cells did not exhibit reduced resistance to PEM with the phosphorylation of AKT in common. Significant inhibition of AKT phosphorylation almostly restored sensitivity to PEM after silencing of both EGFR and ErbB3. The phosphatidylinositol-3-kinase/protein base $\mathrm{B}$ (PI3K/AKT) is involved in a variety of tumor biological markers as a classic survival signaling pathway of anti-apoptosis. This pathway plays a major role in tumor development and the potential tumor response to chemotherapy. Studies found that sustained activation of the PI3K/AKT pathway is related to acquired resistance to chemotherapy (34). Together, these studies outline that PI3K/AKT signaling may be a feasible pathway for PEM-resistance.

Gene polymorphisms or mutations may also influence the response to PEM. Although patients with EGFR mutations respond to TKIs, the second-site point mutation of the EGFR is a major cause of acquired resistance to TKIs $(35,36)$. Increasing EGFR gene copy may be a more valuable marker than EGFR mutations in the prognosis of NSCLC with TKI treatment (37). Research also showed that gefitinib treatment led to increased ErbB3 mRNA levels (38). Given that patients with overexpression of ErbB3 in lung cancer are likely to benefit from EGFR tyrosine kinase inhibitors (39), we may turn to EGFR tyrosine kinase inhibitors based on the expression of EGFR and ErbB3 when tumors treated with PEM progress. Prospective clinical studies are required to confirm the relationship between gene amplification and chemosensitivity or therapy transformation. 
In summary, drug-resistance is the result of the influence of multiple factors together. Upregulation of gene expression is one of the important factors. Our results demonstrated that overexpression of EGFR or ErbB3 may be a predictive marker for patients treated with PEM. The possible mechanism of PEM resistance in A549/PEM cells may be associated with overexpression of EGFR and/or ErbB3 through the PI3K/AKT signaling pathway. Our study showed that the expression of EGFR and ErbB3 increased, while structure changes in the genes were undetermined. It is possible that a secondary mutation of EGFR hindered the effect of PEM. Therefore, further study of the resistant mechanisms and the impact of ErbB genes in PEM resistance is warranted.

\section{Acknowledgements}

The authors are grateful to Dr Hongming Zhai, Department of Chemistry, Lanzhou University, Lanzhou, P.R. China, for the assistance on the docking studies by SYBYL 7.3 software. This study was supported by the Jieping Wu Foundation of China (no. 320.6753.1219), and the Youth Foundation of the Affiliated Hospital of the Medical College, Qingdao University (AHMCQ201232). We also thank the Affiliated Hospital of the Medical College, Qingdao University Research Fund for financial support.

\section{References}

1. Jemal A, Bray F, Center MM, Ferlay J, Ward E and Forman D Global cancer statistics. CA Cancer J Clin 61: 69-90, 2011.

2. Herbst RS, Heymach JV and Lippman SM: Lung cancer. N Engl J Med 359: 1367-1380, 2008.

3. Schiller JH, Harrington D, Belani CP, et al: Comparison of four chemotherapy regimens for advanced non-small-cell lung cancer. N Engl J Med 346: 92-98, 2002.

4. Assaraf YG: Molecular basis of antifolate resistance. Cancer Metastasis Rev 26: 153-181, 2007.

5. Furrukh M, Al-Moundhri M, Zahid KF, Kumar S and Burney I: Customised, individualised treatment of metastatic non-smallcell lung carcinoma (NSCLC). Sultan Qaboos Univ Med J 13: 202-217, 2013

6. Longo-Sorbello GS, Chen B, Budak-Alpdogan T and Bertino JR: Role of pemetrexed in non-small cell lung cancer. Cancer Invest 25: 59-66, 2007.

7. Scagliotti GV, Parikh P, von Pawel J, et al: Phase III study comparing cisplatin plus gemcitabine with cisplatin plus pemetrexed in chemotherapy-naive patients with advanced-stage non-small-cell lung cancer. J Clin Oncol 26: 3543-3551, 2008.

8. Esteban E, Casillas M and Cassinello A: Pemetrexed in first-line treatment of non-small cell lung cancer. Cancer Treat Rev 35: 364-373, 2009.

9. Ceppi P, Volante M, Saviozzi S, et al: Squamous cell carcinoma of the lung compared with other histotypes shows higher messenger RNA and protein levels for thymidylate synthase. Cancer 107 1589-1596, 2006.

10. Zhang D, Ochi N, Takigawa N, et al: Establishment of pemetrexed-resistant non-small cell lung cancer cell lines. Cancer Lett 309: 228-235, 2011.

11. Wu SG, Yang CH, Yu CJ, et al: Good response to pemetrexed in patients of lung adenocarcinoma with epidermal growth factor receptor $(E G F R)$ mutations. Lung Cancer 72: 333-339, 2011.

12. Benavente S, Huang S, Armstrong EA, et al: Establishment and characterization of a model of acquired resistance to epidermal growth factor receptor targeting agents in human cancer cells. Clin Cancer Res 15: 1585-1592, 2009.

13. Giltnane JM, Moeder CB, Camp RL and Rimm DL: Quantitative multiplexed analysis of ErbB family coexpression for primary breast cancer prognosis in a large retrospective cohort. Cancer 115: 2400-2409, 2009.

14. Sharma SV and Settleman J: ErbBs in lung cancer. Exp Cell Res 315: 557-571, 2009.
15. Hayashi M, Inokuchi M, Takagi Y, et al: High expression of HER3 is associated with a decreased survival in gastric cancer. Clin Cancer Res 14: 7843-7849, 2008.

16. Mimeault M, Hauke R and Batra SK: Recent advances on the molecular mechanisms involved in the drug resistance of cancer cells and novel targeting therapies. Clin Pharmacol Ther 83: 673-691, 2008

17. Schmidt $M$ and Lichtner RB: EGF receptor targeting in therapyresistant human tumors. Drug Resist Updat 5: 11-18, 2002.

18. Desbois-Mouthon C: The HER3/ErbB3 receptor: a promising target in cancer drug therapy. Gastroenterol Clin Biol 34: 255-259, 2010.

19. Blivet-Van Eggelpoël MJ, Chettouh H, Fartoux L, et al: Epidermal growth factor receptor and HER-3 restrict cell response to sorafenib in hepatocellular carcinoma cells. J Hepatol 57: 108-115, 2012.

20. Lu S, Zheng W, Ji L, et al: Synthesis, characterization, screening and docking analysis of 4-anilinoquinazoline derivatives as tyrosine kinase inhibitors. Eur J Med Chem 61: 84-94, 2013.

21. Zhou Y, Ling XL, Li SW, Li XQ and Yan B: Establishment of a human hepatoma multidrug resistant cell line in vitro. World $\mathrm{J}$ Gastroenterol 16: 2291-2297, 2010.

22. Ikari A, Sato T, Watanabe R, Yamazaki Y and Sugatani J: Increase in claudin-2 expression by an EGFR/MEK/ERK/c-Fos pathway in lung adenocarcinoma A549 cells. Biochim Biophys Acta 1823: 1110-1118, 2012.

23. Kaszubiak A, Holm PS and Lage H: Overcoming the classical multidrug resistance phenotype by adenoviral delivery of anti-MDR1 short hairpin RNAs and ribozymes. Int J Oncol 31: 419-430, 2007.

24. Amati P and Lago C: Sensitivity to amphotericin B of in vitro established cell lines. Nature 247: 466-469, 1974.

25. Snow K and Judd W: Characterisation of adriamycin- and amsacrine-resistant human leukaemic $\mathrm{T}$ cell lines. Br J Cancer 63: 17-28, 1991.

26. Lu X, Errington J, Curtin NJ, Lunec J and Newell DR: The impact of $p 53$ status on cellular sensitivity to antifolate drugs. Clin Cancer Res 7: 2114-2123, 2001.

27. Hsu HF, Huang KH, Lu KJ, et al: Typhonium blumei extract inhibits proliferation of human lung adenocarcinoma A549 cells via induction of cell cycle arrest and apoptosis. J Ethnopharmacol 135: 492-500, 2011

28. Heinemann L, Simpson GR, Annels NE, et al: The effect of cell cycle synchronization on tumor sensitivity to reovirus oncolysis. Mol Ther 18: 2085-2093, 2010.

29. Hanauske AR, Eismann U, Oberschmidt O, et al: In vitro chemosensitivity of freshly explanted tumor cells to pemetrexed is correlated with target gene expression. Invest New Drugs 25: 417-423, 2007.

30. Ozasa H, Oguri T, Uemura T, et al: Significance of thymidylate synthase for resistance to pemetrexed in lung cancer. Cancer Sci 101: 161-166, 2010.

31. Wu MF, Hsiao YM, Huang CF, et al: Genetic determinants of pemetrexed responsiveness and nonresponsiveness in non-small cell lung cancer cells. J Thorac Oncol 5: 1143-1151, 2010.

32. Sebastian S, Settleman J, Reshkin SJ, Azzariti A, Bellizzi A and Paradiso A: The complexity of targeting EGFR signalling in cancer: from expression to turnover. Biochim Biophys Acta 1766: 120-139, 2006

33. Durmuş Tekir S, Yalçin Arga K and Ulgen KO: Drug targets for tumorigenesis: insights from structural analysis of EGFR signaling network. J Biomed Inform 42: 228-236, 2009.

34. Fresno Vara JA, Casado E, de Castro J, Cejas P, Belda-Iniesta C and González-Barón M: PI3K/Akt signalling pathway and cancer. Cancer Treat Rev 30: 193-204, 2004.

35. Kosaka T, Yatabe Y, Endoh H, et al: Analysis of epidermal growth factor receptor gene mutation in patients with non-small cell lung cancer and acquired resistance to gefitinib. Clin Cancer Res 12: 5764-5769, 2006

36. Yamamoto $\mathrm{H}$, Toyooka $\mathrm{S}$ and Mitsudomi $\mathrm{T}$ : Impact of $E G F R$ mutation analysis in non-small cell lung cancer. Lung Cancer 63: 315-321, 2009.

37. Cappuzzo F, Hirsch FR, Rossi E, et al: Epidermal growth factor receptor gene and protein and gefitinib sensitivity in non-smallcell lung cancer. J Natl Cancer Inst 97: 643-655, 2005.

38. Grøvdal LM, Kim J, Holst MR, Knudsen SL, Grandal MV and van Deurs B: EGF receptor inhibitors increase ErbB3 mRNA and protein levels in breast cancer cells. Cell Signal 24: 296-301, 2012.

39. Kawano O, Sasaki H, Endo K, et al: ErbB3 mRNA expression correlated with specific clinicopathologic features of Japanese lung cancers. J Surg Res 146: 43-48, 2008. 